\title{
In memoriam of Professor Jesús Mur (1961-2020)
}

\section{Fernando López Hernández ${ }^{1}$}

\section{Published online: 26 April 2021}

(C) The Author(s), under exclusive licence to Springer Nature Switzerland AG 2021

We are deeply saddened by the loss of our dear friend and colleague Jesús Domingo Mur Lacambra. We were profoundly sorrowed by the news on September 11, 2020 when his wife Pili called to tell us of his passing. From that day all of us have missed him greatly.

Jesús Mur was born Binéfar (Spain), on December 20, 1961. The only child of a working-class family, he soon moved to the city of Zaragoza (capital of the region of Aragón) to further his education. He remained closely connected to that city all his life, and it marked his character. ${ }^{1}$ He studied in the Economics Faculty at the University of Zaragoza (Spain) where he obtained his degree in 1985. That same year, he received a scholarship from the Regional Government of Aragon to undertake his doctoral studies. The following year, in 1986, he began working as an assistant professor at the University of Zaragoza, where he would remain for the duration of his career. His doctoral thesis, directed by professor Antonio Aznar, ${ }^{2}$ was titled "Correlación espacial: un estudio de Monte Carlo" (Spatial Correlation: A Monte Carlo Study) and was defended in 1990. It was the first recognized research carried out in Spain in the area of Spatial Econometrics, and it presented one of the earliest implementations of the Monte Carlo method in this field. An extract from this research was published in Mur (1992).

Jesús Mur's interest in Spatial Econometrics was not accidental. Professor Jean Paelinck (Paelinck and Klaassen 1979), the father of Spatial Econometrics, visited the Economics Faculty at the University of Zaragoza, invited by professor Antonio Aznar, on various occasions. Jesús was most likely attracted by professor Paelinck's personality and by the novelty of this branch of Econometrics, which was then emerging as a new discipline with great research possibilities. Encouraged by

\footnotetext{
${ }^{1}$ In Spain, those born in the region of Aragón (Zaragoza is the capital) are known for being willful and headstrong. This surely helped him succeed in whatever goal he set for himself, including his career objectives.

2 Professor Antonio Aznar is one of the first full professors of Econometrics in Spain. With great intuition for Econometrics, he always thought that Spatial Econometrics should be a part of the research agenda. Professor Aznar had a continuously good relationship with professor Jean Paelinck.
}

Fernando López Hernández

fernando.lopez@upct.es

1 Universidad Politécnica de Cartagena, Cartagena, Murcia, Spain 
professor Aznar and motivated by his interest in expanding the topic of his thesis, Jesús contacted professor Paelinck to carry out a postdoctoral fellowship. In 1993, Jesús arrived at the Department of Theoretical Spatial Econometrics (Erasmus Universiteit, Rotterdam, Holland) under the supervision of professor Paelinck. This year-long fellowship proved to be pivotal to his career, not only as a result of the close friendship which developed between the two of them but also because it reinforced the interest Jesús had in Spatial Econometrics, determining his professional trajectory as a researcher.

From Mur's seminal paper (1992), and from his experiences in Rotterdam, a number of contributions to the topic of Spatial Econometrics were produced. Although these first papers were written alone (e.g. Mur 1999), he soon began to collaborate with various friends and colleagues who shared his interests. Quantitatively oriented, his research was centered on issues of Regional Analysis, Economic Geography, and Spatial Econometrics, which were the areas that continued to interest him throughout his professional life. Three of the areas in which Jesús focused his attention are highlighted here: spatial dependence tests, the selection of spatial regression models, and the selection of the $\mathrm{W}$ matrix.

Jesús's scientific contribution has most notably been made through his research into the Lagrange Multipliers method (LM) and its evaluation using Monte Carlo simulations. A large part of this contribution was centered on the development of LM tests for spatial regression models with cross-sectional data (e.g. Mur 1999; Mur and Angulo 2006; Mur et al. 2008, 2009, 2010). These publications have significantly advanced the flexibilization of the concept of spatial dependence, identifying the presence of local spatial dependence structures (Mur et al. 2008), or testing the presence of parametric instability in spatial regression models (Mur et al. 2009). Later, with the popularization of spatial regression models for panel data, Jesús also demonstrated his interest in these types of specifications, developing various tests for spatial panel models. We highlight his contribution to the development of the LM for Spatial Seemingly Unrelated Regression model tests (López et al. 2010a, b). The tests which were developed in this paper, along with the new contributions which Jesús worked on until the end, have been offered to the general public through the creation of the spsur R-package (Mínguez et al. 2020), which is currently available in CRAN repository. Although, as previously mentioned, the majority of his contributions apply the LM methodology, he also used other methodologies to identify the presence of spatial structures in regression models (López et al. 2010a, b; López et al. 2011).

His experience in the development of all these tests helped to reorient his research toward the problem of the selection of spatial regression models (Mur and Angulo 2006, 2007, 2009; López et al. 2014). In these papers, making use of a battery of tests, a strategy was designed to facilitate the identification of the functional form of spatial dependence. This is the area of his work that has attracted the most attention from the scientific community involved in the selection of models. Finally, we cannot forget the interest he showed in identifying the $\mathrm{W}$ matrix during the last years of his life. Various articles dealing with this topic were published, and again, coauthored with his colleagues (Angulo et al. 2017, 2018; Herrera et al. 2019). 
Jesús enjoyed his work, and although his main contributions were focused on the above three topics, he was also interested in other areas, always accompanied by good friends. Some examples are: the detection of outliers in space (Mur and Lauridsen 2007); causal relationships (Herrera et al. 2014); the location of industrial production (Maté et al. 2017) or productivity analysis at the regional level, natural resource management, and the prediction of regional series (Angulo et al. 2014).

He formed the Hispalink-Aragón group along with his colleague Francisco Javier Trívez, and during the period 1996-2020, this group worked to provide a perspective of economic growth in the region of Aragón. Their contributions were integrated into those made by other Hispalink groups (one group per Spanish region), thereby offering general and sectorial views of regional economic growth. His work remains in the form of publications and reports which can be consulted at http://www.hispalink.es/.

As a result of all this research, Jesús brought together and directed a small but strong research group made up of colleagues from various Spanish universities. This group's work has been recognized on a national and international level through different research projects funded by Spanish R\&D\&i plans. The vast majority of these research projects were focused on Spatial Econometrics. Jesús always displayed excellent skills in directing and coordinating this group, which has established a precedent in Spanish universities.

Finally, he served on the editorial board of journals such as Papers in Regional Science or the Journal of Spatial Econometrics. Also, Jesús has been a guest editor of several journals (Journal of Geographical Systems; Estadística Española; Spatial Economic Analysis) and of peer-reviewed articles in a multitude of specialized journals.

But, undoubtedly, one of the academic activities that Jesús felt most enthusiastic about was organizing and promoting a small Spatial Econometric seminar in honor of professor Jean Paelinck. Jesús Mur organized the first edition at the University of Zaragoza in 1999, gathering together a few Spanish researchers interested in the subject of Spatial Econometrics as well as a select number of European researchers. This seminar, which continues to be held biannually, represents a benchmark in Europe and maintains its original objective of putting experienced and new researchers in contact with each other to create bonds and encourage future collaboration. The Jean Paelinck seminar remains active today and will continue to be the focus of attention for those colleagues interested in the topic of Spatial Econometrics. That same year, in 1999, the Spatial Econometric Association (SEA) was born with the aim of joining together all researchers interested in Spatial Econometrics. Professor Mur participated in this initiative as a founding member.

Jesús Mur was also an excellent professor. His teaching activity mainly involved teaching in Econometrics and Mathematics to undergraduate students of Economics at the University of Zaragoza, but he also trained a new generation of doctoral students, teach different specialized courses. His courses were focused on specific methodological topics of Spatial Econometrics; mainly spatial panels. In these courses, which required many hours of preparation, Jesús demonstrated enormous skill in presenting complex abstract concepts in an easy-to-understand way. Some of these undergraduate students were attracted by his personality and knowledge and 
developed their doctoral theses under his supervision. These students were able to enjoy the pleasure of both his expertise and his friendship.

Jesús transmitted his passion for Spatial Econometrics and his excitement about advancements in learning to us. He left us at a great moment in his professional development and in a mature stage of production, with deep knowledge about Spatial Econometrics. His best papers had yet to be written. Jesús loved his work and wanted to continue with it up to the last moment, in spite of the severe limitations his illness imposed. He dictated the last paper he was working on to his wife Pili when he could no longer write. I had various video calls with him to finish this last paper still in progress, and it will certainly be painful to finish it without his help and with his memory always present.

Jesús will be profoundly missed by us, by many colleagues in the Spatial Econometric Association, and by his friends all over the world, but overall, by his wife Pili and his children Inés and Miguel. We will never get over his loss. Rest in peace, Jesús.

\section{References}

Angulo A, Atwi M, Barberán R, Mur J (2014) Economic analysis of the water demand in the hotels and restaurants sector: Shadow prices and elasticities. Water Resour Res 50(8):6577-6591

Angulo A, Burridge P, Mur J (2017) Testing for a structural break in the weight matrix of the spatial error or spatial lag model. Spat Econ Anal 12(2-3):161-181

Angulo A, Burridge P, Mur J (2018) Testing for breaks in the weighting matrix. RegSci Urban Econ 68:115-129

Herrera M, Mur J, Ruiz M (2014) Detecting causal relationships between spatial processes. Pap RegSci 95:577-594

Herrera M, Mur J, Ruiz M (2019) A comparison study on criteria to select the most adequate weighting matrix. Entropy 21(2): 160

López FA, Matilla-García M, Mur J, Ruiz M (2010a) A non-parametric spatial independence test using symbolic entropy. RegSci Urban Econ 40(2-3):106-115

López FA, Matilla-García M, Mur J, Ruiz M (2011) Four tests of independence in spatiotemporal data. Pap RegSci 90(3):663-685

López FA, Mur J, Angulo A (2010b) Local estimation of spatial autocorrelation processes. In: Páez A, Gallo J, Buliung R, Dall'erba S (eds) Progress in spatial analysis. Springer, Berlin, pp 93-116

López FA, Mur J, Angulo A (2014) Spatial model selection strategies in a SUR framework. The case of regional productivity in EU. Ann RegSci 53(1):197-220

Maté ML, López FA, Mur J (2017) How do neighboring peer companies influence SMEs' financial behavior? Econ Model 63:104-114

Mínguez R, López FA, Mur J (2020) spsur: an R package for dealing with spatial seemingly unrelated regression models. J Stat Softw (submitted)

Mur J (1992) Contrastes de autocorrelaciónespacial: Unestudio de Monte Carlo. Estadística Española 130:285-308

Mur J (1999) Testing for spatial autocorrelation: moving average versus autoregressive processes. Environ Plan A 31(8):1371-1382

Mur J, Angulo A (2006) The spatial Durbin model and the common factor tests. Spat Econ Anal 1(2):207-226

Mur J, Angulo A (2009) Model selection strategies in a spatial setting: some additional results. RegSci Urban Econ 39(2):200-213

Mur J, Angulo A (2007) Clues for discriminating between moving average and autoregressive models in spatial processes. Span Econ Rev 9(4):273-298 
Mur J, Lauridsen J (2007) Outliers and spatial dependence in cross-sectional regressions. Environ Plan A 39(7):1752-1769

Mur J, López FA, Angulo A (2008) Symptoms of instability in models of spatial dependence. Geogr Anal 40(2):189-211

Mur J, López FA, Angulo A (2009) Testing the hypothesis of stability in spatial econometric models. Pap RegSci 88(2):409-444

Mur J, López FA, Herrera M (2010) Testing for spatial effects in Seemingly Unrelated Regressions. Spat Econ Anal 5(4):399-440

Paelinck J, Klaassen L (1979) Spatial econometrics. Saxon House

Publisher's Note Springer Nature remains neutral with regard to jurisdictional claims in published maps and institutional affiliations. 